\title{
O BERGSONISMO DE GILLES DELEUZE
}

\author{
Sandro Kobol FORNAZARI ${ }^{1}$
}

- RESUMO: Este texto é uma apresentação da interpretação feita por Gilles Deleuze da filosofia de Henri Bergson. Procura-se enfocar os temas que viriam a ser retomados pela filosofia deleuziana, sendo desenvolvidos em Diferença e repetição e a partir dessa obra. Dentre os mais relevantes, encontrase o tema da ontologia afirmativa, que envolve a passagem do virtual para o atual através do processo de diferenciação do ser. O ser não deixa de ter existência ao atualizar-se, mas ele diferencia a si mesmo nesse processo, individuando-se como as coisas presentes na experiência. O ser é, desse modo, pré-individual e pré-subjetivo. Em Bergson, haveria a coexistência virtual de todos os graus de diferenças na duração.

- PALAVRAS-CHAVE: intuição; virtual; atual; diferenciação; memória

Tudo no mundo começou com um sim. Uma molécula disse sim a outra molécula e nasceu a vida. Mas antes da pré-história havia a pré-história da préhistória e havia o nunca e havia o sim. Sempre houve. Não sei o quê, mas sei que o universo jamais começou. (Clarice Lispector, A hora da estrela)

Os conceitos de atual e virtual atravessam a obra filosófica de Gilles Deleuze, desde os trabalhos sobre Henri Bergson até seu último escrito, "A imanência: uma vida..." A partir desses conceitos, Deleuze elaborará uma ontologia afirmativa na medida em que haveria entre o virtual e o

1 Doutorando em filosofia pela Universidade de São Paulo. 
atual um processo positivo de diferenciação, ou seja, uma produção da multiplicidade atual a partir da multiplicidade virtual do ser, que ele passará a designar por plano de imanência. Ali, o próprio pensamento se constitui como possibilidade de pensar, sem que haja um eu por trás da ação de pensar, sem que haja a individuação de um sujeito e de um objeto. Os seres singulares (multiplicidade atual) seriam fluxos que se recortam do plano de imanência (multiplicidade virtual), que se conjugam com outros fluxos, são relações pré-subjetivas, multiplicidades que devem e só se produzirão como singularidades como resultado dessas interações de forças.

A vida imanente carrega as singularidades sob o aspecto de virtualidades que se atualizam como coisas. Isto não significa que ao virtual falte realidade, na medida em que ele é um empenho num processo de atualização, seguindo o plano que lhe dá sua realidade própria, ele é real sem ser atual. Trata-se, portanto, de discutir, a partir dos termos centrais dessa ontologia, como se dá esse processo em que a multiplicidade atual se produz e se destaca do plano de imanência sem que isso signifique alguma perda ou ganho em termos de realidade. Para isso, faz-se necessário partir da compreensão da releitura feita por Deleuze da obra de Bergson, objetivo a que nos propusemos e que deu ensejo a este escrito.

"Um grande filósofo é aquele que cria novos conceitos: esses conceitos ultrapassam as dualidades do pensamento ordinário e, ao mesmo tempo, dão às coisas uma verdade nova, uma distribuição nova, um recorte extraordinário." São estas as palavras com que Deleuze abre seu artigo sobre Bergson para a coletânea Les philosophes célèbres, editada por Maurice Merleau-Ponty em 1956. Desde o início, procura deixar transparente que se trata de uma homenagem a um filósofo que figura entre os maiores, que soube impor ao debate filosófico novos conceitos, com destaque para os de duração, memória, impulso vital e intuição. Contudo, homenagear é um verbo com uma significação especial para Deleuze, pois não apenas expressa sua admiração e respeito à obra acabada de Bergson, mas indica que sua criação filosófica não se esgota em si mesma, permanecendo viva e inspiradora de novas criações, tal como os desenvolvimentos da própria filosofia deleuziana dará mostras.

Dez anos depois, em 1966, Deleuze publica Bergsonismo, procedendo a uma análise bastante detalhada da gênese dos conceitos bergsonianos a partir das etapas do método. Seguiremos aqui com alguma proximidade essa análise, de modo que não percamos o essencial das explicações dadas por Deleuze de sua interpretação da filosofia de Bergson. 


\section{A intuição como método}

A intuição é o método usado por Bergson para apreender aquilo que faz a coisa ser o que ela é, em sua diferença a respeito de tudo aquilo que não é ela. A intuição já pressupõe a duração na medida em que a diferença interna da coisa é diferença em relação a si mesma, pois ao diferenciar-se ela muda de natureza fazendo tensionar ou distender a própria duração. Assim, se desejamos apreender a diferença a partir do método intuitivo, já o fazemos desde um ponto de vista interno à duração e isso seguindo três passos que determinam as próprias regras do método.

(a) Primeira regra: veracidade e falsidade dos problemas. Trata-se do poder de constituir os próprios problemas, de bem apresentar os problemas, o que significa inventá-los, criar os seus termos. E se o problema é bem apresentado, embora ele possa ainda permanecer encoberto, ele encerra em si sua solução, que cedo ou tarde virá. A solução virá em função dos termos de que se dispõe para apresentá-lo, das condições sob as quais é engendrado. Mas com base em que se poderia definir um problema como verdadeiro ou como falso, aplicar o critério do verdadeiro e do falso à própria atividade de apresentação de problemas? Bergson define dois tipos de falsos problemas: os inexistentes e os mal apresentação. O não-ser, a desordem e o possível, por exemplo, são problemas inexistentes. São problemas inexistentes porque são formas de negação daquilo que é a própria verdade, ou seja, o ser, a ordem e o existente. Tomemos a idéia de não-ser como exemplo. A idéia de não-ser é a soma da idéia prévia de ser, da operação lógica de negação generalizada e do motivo de tal operação, qual seja, quando um ser não nos convém e o apreendemos apenas como ausência daquilo que nos interessa. Quando perguntamos pelo não-ser, estamos numa ilusão fundamental: pressupomos a existência do não-ser em relação ao ser, como se este viesse apenas preencher o vazio. É o que Bergson chama de "movimento retrógrado do verdadeiro", que leva a supor que o ser preceda a si mesmo, preceda ao ato de sua própria criação, retroprojetando uma imagem de si mesmo num não-ser supostamente primordial. O outro tipo de falso problema se refere aos mistos mal analisados, quando se juntam arbitrariamente coisas que diferem por natureza. O próprio conceito geral de Ser é um misto mal analisado, pois em vez de apreendermos as diferentes realidades que se substituem umas às outras, nós confundimos tudo na homogeneidade do Ser e a partir disso permitimos que surja a idéia de não-ser. Em suma, os falsos problemas, dos dois tipos, têm início no 
momento em que se negligenciam as diferenças de natureza: a idéia de não-ser nasce de uma idéia geral de Ser como misto mal analisado. Tal seria a ilusão do pensamento, tanto científico quanto metafísico, ou seja, ver diferenças de grau (por exemplo, o não-ser que aparece ora como mais ora como menos que o ser) quando há diferenças de natureza. Há de se verificar quanto estamos mergulhados nessa ilusão, que é inseparável de nossa condição, quanto essa ilusão é inevitável. É contra ela justamente que Bergson vem suscitar a intuição, que vai reencontrar as diferenças de natureza que estão sob as diferenças de grau, comunicando, além disso, à inteligência os critérios para distinguir os verdadeiros e os falsos problemas.

(b) Segunda regra: reencontrar as articulações do real. Aqui se trata de lutar contra a ilusão de ver diferenças de grau onde há diferenças de natureza. Para isso, deve-se dividir um misto qualquer segundo suas articulações naturais, ou melhor, segundo seus elementos que diferem por natureza. Trata-se de buscar nas misturas propiciadas pela experiência aquilo que elas têm de puro, quer dizer, ao ultrapassar a experiência em direção às condições dessa experiência real, dividindo-a em puras presenças, encontrar-se-á o que difere por natureza ou, em uma palavra, suas tendências. Por exemplo, lembrança e percepção se encontram tão misturadas em nós que não sabemos reconhecer o que cabe a uma e o que cabe à outra a não ser como diferenças de grau, e não somos capazes de distinguir na representação as presenças puras da matéria e da memória. A intuição como método propõe distinguir, isto é, dividir o misto de acordo com suas tendências que diferem por natureza. Ora, essa tarefa indica que é necessário ir além da experiência real em que a condição humana nos obriga a viver. Bergson aponta a necessidade de "buscar a experiência em sua fonte, ou melhor, acima dessa viravolta decisiva, na qual, inflectindo-se no sentido de nossa utilidade, ela se torna propriamente experiência humana". ${ }^{2}$ Esse ultrapassamento, no entanto, não consiste em ir na direção de conceitos gerais e abstratos, mas em encontrar as articulações das quais as particularidades da experiência real dependem. E se se podem ali encontrar conceitos, estes serão talhados sobre a própria coisa, convindo somente a ela e não sendo mais amplo do que aquilo de que ele deve dar conta. Deleuze vê nessa desarticulação do real em vista de suas diferenças de natureza a constituição de um empirismo superior, que será comple-

2 Bergson, H. Oeuvres. Paris: PUF, 1963, p. 321. Apud Deleuze, 1999, p. 18. 
mentado por um movimento no sentido inverso, agora de convergência entre as linhas, de reintegração após a diferenciação até o ponto virtual para o qual as linhas convergem (imagem virtual do ponto de partida, situada também além da viravolta da experiência), tornando-nos aptos, através de um probabilismo superior, a resolver os problemas, relacionar a condição ao condicionado, sem que subsista então qualquer distância entre eles. E assim o problema, tendo sido bem apresentado, tende a resolver-se por si mesmo.

(c) Terceira regra: a intuição supõe a duração. A intuição consiste em pensar em termos de duração porque somente nela se encontra o poder de variar qualitativamente em relação a si mesma, de ser portadora das diferenças de natureza. Quando dividimos uma coisa em suas articulações naturais, por exemplo, um pedaço de açúcar, temos de um lado o espaço, que somente nos dá diferenças de grau entre esse pedaço de açúcar e qualquer outra coisa, e de outro lado temos a duração, um modo de ser no tempo, que se revela quando o açúcar se dissolve, quando observamos que ele difere por natureza de si mesmo mas também das outras coisas. Desse modo, é na duração que se dão as diferenças de natureza (alteração), melhor, ela é a multiplicidade das diferenças, enquanto que o espaço não é mais que o lugar e o conjunto das diferenças de grau (aumento e diminuição). A intuição é o movimento por meio do qual saímos de nossa própria duração para afirmarmos ou reconhecermos imediatamente a existência de outras durações ou de diferenças de natureza. Apenas por meio dela somos capazes de apresentar os verdadeiros problemas e de nos livrar da ilusão propiciada pelos mistos que se apresentam como diferenças de grau na nossa experiência primeira do mundo, isto é, na matéria e na extensão.

\section{A duração como dado imediato}

A experiência sempre propicia um misto de espaço e duração; vimos, porém, que se trata em Bergson de ultrapassar a experiência vivida, restaurando as coisas em seu dado imediato. Para isso, é preciso dividir o misto, reencontrar a diferença da coisa, aquilo que a faz ser o que ela é. Vimos também que tal divisão do misto espaço e duração leva a duas direções das quais somente uma é pura, sendo o espaço a impureza que desnatura a duração. O seguinte esquema nos permite visualizar as características atribuídas ao espaço e à duração, sendo que cada um dos lados da divisão revela um tipo de multiplicidade: 


\begin{tabular}{ll}
\hline \multicolumn{1}{c}{ Espaço } & \multicolumn{1}{c}{ Duração } \\
\hline $\begin{array}{l}\text { Exterioridade sem sucessão, distinções } \\
\text { extrínsecas ou "cortes" homogêneos } \\
\text { e descontínuos. }\end{array}$ & $\begin{array}{l}\text { Sucessão puramente interna, sem } \\
\text { exterioridade, heterogênea e contínua. }\end{array}$ \\
\hline $\begin{array}{l}\text { Multiplicidade numérica, descontínua } \\
\text { e atual: }\end{array}$ & $\begin{array}{l}\text { Multiplicidade virtual e contínua, } \\
\text { multiplicidade de exterioridade, de } \\
\text { simultanel ao número: multiplicidade } \\
\text { diferenciação quantitativa, diferença } \\
\text { interna, de sucessão, de fusão, } \\
\text { organização, heterogeneidade, } \\
\text { discriminação qualitativa, diferença } \\
\text { de natureza. }\end{array}$ \\
\hline
\end{tabular}

Bergson distingue a multiplicidade qualitativa e contínua da duração (virtual) opondo-a à multiplicidade quantitativa ou numérica do espaço (atual). Tal distinção é bem diferente daquela que opõe o Uno ao Múltiplo, buscando uma suposta unidade do Múltiplo, sem ser capaz de sair de um movimento abstrato. A multiplicidade numérica é a imagem ou a matéria, é o que não muda de natureza ao dividir-se, o que só tem diferenças de grau e estas, realizadas ou não, são sempre atuais pois tais divisões já estão presentes na imagem do objeto, isto é, ainda que apenas como possibilidades, as partes da matéria são percebidas atualmente e não virtualmente. Novas impressões poderiam substituir a idéia atual que temos de tal imagem, sabemos de antemão essa possibilidade e sabemos que ela não significa mais que uma mudança de grau e não uma mudança na natureza da coisa. É ao que se dá o nome de objetivo.

A multiplicidade qualitativa, por sua vez, é o subjetivo. A duração divide-se e, a cada vez que se divide, ela muda de natureza; em cada etapa, seus elementos estão presentes, mas indiscerníveis, irrealizados. Ao atualizarem-se, estes elementos serão fruto de uma mudança de natureza. Assim, a duração é o virtual à medida que, no movimento de sua atualização que se faz por diferenciação, se atualiza por linhas divergentes. Ir do virtual à sua atualização significa habitar a dimensão puramente temporal e não mais espacial, criando linhas de diferenciação. Há, portanto, continuidade (no processo temporal de atualização) e heterogeneidade (porque a atualização se faz por diferenciações que correspondem às diferenças de natureza).

Deleuze vê nessa distinção entre os dois tipos de multiplicidade, apreendidos a partir da análise da experiência vivida, uma crítica de Bergson à dialética em geral e ao hegelianismo em particular, porque a noção de multiplicidade faz com que evitemos pensar em termos de Uno e Múltiplo ou de compor o real a partir de abstratos, conceitos demasiado amplos, que apenas compensam sua insuficiência apelando ao 
conceito oposto, igualmente insuficiente, esvaziados ambos de toda realidade, por exemplo, quando se diz que o Uno já é múltiplo, ou que o Ser passa ao não-ser e produz o devir. A multiplicidade qualitativa não deve ser confundida com o múltiplo. Da mesma forma, pensar nas diferenças de natureza é rejeitar as formas do negativo: o negativo como degradação do ser ou como oposição ao ser, supostos movimentos a partir dos quais as coisas se produziriam.

Com Bergson, podemos pensar numa diferença de natureza entre dois "seres" ou, em outras palavras, num processo de diferenciação, sem recorrermos a conceitos abstratos como os conceitos de ser e de não-ser. Dirá Bergson: "O que verdadeiramente importa à filosofia é saber qual unidade, qual multiplicidade, qual realidade superior ao uno e ao múltiplo abstratos é a unidade múltipla da pessoa." ${ }^{3}$ Há, portanto, uma crítica do negativo e das idéias gerais abstratas quando se propõe a diferença de natureza entre dois tipos de multiplicidade.

Mas, e quanto às multiplicidades numéricas que se apresentam como atuais, não têm elas uma duração? A experiência da duração parece ser puramente psicológica, pois é preciso uma consciência que rememore as mudanças das coisas exteriores para que se possa dizer que elas se modificam. Parece que, fora de nós, apenas haveria o presente ou a simultaneidade. No entanto, a experiência física do movimento faz com que as coisas pareçam suceder-se e não se disporem todas ao mesmo tempo; o espaço percorrido pelo móvel forma uma multiplicidade numérica cujas partes são todas atuais e diferem apenas em grau. Além disso, ao mesmo tempo, o movimento puro é alteração, multiplicidade virtual qualitativa. Assim, se somos capazes de considerar o movimento como momentos sucessivos de nossa duração, devemos inevitavelmente considerar que as coisas mudaram e que é preciso que o movimento das coisas não seja apenas duração como experiência psicológica, e sim que as coisas participem diretamente na própria duração. A duração psicológica é uma abertura a uma duração ontológica, levando-se em conta inclusive que ela é definida como multiplicidade.

Contudo, haverá uma só duração ou várias durações? Além disso, se as coisas têm uma duração, o espaço não deveria ser mais que uma

3 Idem, p. 1.409. Apud Deleuze, 1999, p. 34. Aparentemente consciente do risco de que, em Bergson, a distinção entre objetivo e subjetivo possa ser considerada não ontológica, mas psicológica, Deleuze cita a referência a uma "unidade múltipla da pessoa" de forma a introduzir a pessoa como participante na própria duração, conforme veremos na seqüência. 
simples forma de exterioridade, mais que uma impureza que vem comprometer a pureza da duração?

\section{A memória como coexistência virtual}

Bergson apresenta a duração como idêntica à memória e o faz considerando que há dois aspectos da memória: a memória-lembrança, como conservação do passado no presente e, portanto, cada novo presente contém uma imagem crescente do passado, e a memória-contração, como acumulação do passado no presente, sendo que os momentos sucessivos da duração se contraem ou se condensam um no outro. Nesse sentido, devemos investigar o mecanismo que torna possível à duração tornar-se memória.

O cérebro não é capaz de conservar as lembranças porque ele faz parte da objetividade, não tem diferença de natureza em relação aos outros estados de matéria e estes não têm poder de conservação. A lembrança, por sua vez, faz parte da linha de subjetividade e, desse modo, ela só pode conservar-se na duração. Como a duração é o prolongamento incessante no presente de um passado indestrutível, conclui-se que a lembrança se conserva a si mesma.

Isso se dá dessa forma porque há, entre a matéria e a memória (a percepção pura e a lembrança pura, o presente e o passado) uma diferença de natureza. O passado sobrevive em si mesmo, pois ele não deixa de ser. Se temos dificuldade de pensar nessa conservação da lembrança em si mesma é porque confundimos o ser com o ser-presente. Mas em Bergson se passa justamente o contrário, o presente não é, mas age, é a forma sob a qual o ser se consome e se põe fora de si, ele é puro devir; o passado, por sua vez, deixou de ser útil, mas nunca deixa de ser: o passado é, ele é o em-si do ser e é como passado que o ser se conserva em si. O presente a cada instante deixa de ser, o passado é incessantemente e é nisso que consiste a diferença de natureza entre eles. Por conseguinte, o psicológico diz respeito ao presente, à percepção pura a partir dos estados de matéria, e a lembrança não tem uma existência psicológica: o passado é extrapsicológico, ele é a ontologia pura, a lembrança pura que se dirige ao ser como ele é em si, a lembrança pura é o virtual.

Lembrar é instalar-se de súbito no passado. Tal como perceber as coisas é percebê-las ali onde elas estão (e não em nós), apreender o 
passado é apreendê-lo onde ele está, isto é, em si mesmo (e não em nós, em nosso presente). Devemos admitir, assim, que há um passado em geral como elemento ontológico, que nunca deixa de ser e que ainda é condição de todos os passados como passagem de um presente particular. A existência psicológica da lembrança vem apenas em seguida, depois de termos nos instalado no passado, ali aos poucos ela passa de virtual para atual. ${ }^{4}$

A discussão precedente mostra bem por que a lembrança e a percepção são ilusoriamente consideradas como um misto em que haveria apenas diferenças de grau, qual seja, a imagem como realidade psicológica. Na imagem, vemos o passado reconstituído pelo novo presente que o suscita, a imagem atualiza a lembrança, mas não sem a forçar a uma adaptação às exigências do presente, fazendo da lembrança algo do presente, como se houvesse apenas diferenças de grau entre imagens-lembranças e percepções-imagens. Isso se dá porque temos o hábito de pensar em termos de presente: que o passado só se constitui quando ele deixa de ser presente, que um presente só passa quando um outro o substitui. Porém, para que um novo presente advenha, é preciso que o antigo presente passe ao mesmo tempo em que é presente, é preciso que o presente seja ao mesmo tempo em que é passado, senão ele não passaria jamais; do mesmo modo, o passado não se formaria se não tivesse sido constituído inicialmente quando foi presente. Portanto, o passado coexiste ao presente que ele foi, não se trata de momentos sucessivos. O presente não cessa de passar, o passado não cessa de ser e é através do passado que todos os presentes passam, não fosse assim o passado jamais se constituiria. Assim, Bergson concluirá pela necessidade de haver um passado puro, não um passado derivado do presente, mas um passado que é suposto por ele como condição sem a qual ele não passaria.

Além de passado e presente coexistirem, o passado se conserva em si mesmo, enquanto o presente passa. Por conseguinte, é necessário que seja todo o passado que coexista com cada presente, sendo este o sentido da metáfora do cone que aparece em Matéria e memória, sendo o vértice do cone o presente sob o aspecto de nível mais contraído da duração. A duração é, portanto, coexistência virtual, ou seja, nela coe-

4 Deleuze ressalta que o mesmo vale também para a linguagem, numa espécie de "fundamento ontológico da linguagem": compreendemos o que nos é dito a partir de uma salto, subitamente, no elemento do sentido para só depois ter a atualização do sentido nos sons (percebidos fisiologicamente) e nas imagens (associadas a esses sons psicologicamente). Cf. Deleuze, 1999, p. 44 
xistem todos os níveis ou todos os graus de contração e distensão enquanto pertencentes ao ser em si do passado, de modo que há uma repetição virtual de todo o nosso passado ao mesmo tempo e em todos os níveis distintos que ele traça e que contém, cada nível, todo o nosso passado, num estado mais ou menos contraído.

O problema que Deleuze apresenta, neste ponto, é o de saber de que modo se atualiza essa virtualidade da duração, ou seja, como a lembrança pura chega a ter uma existência psicológica. Não se trata mais da lembrança pura e virtual, que Bergson designa como inconsciente ontológico, mas do inconsciente psicológico, movimento da lembrança, que nasce do presente e tende a se atualizar, a se encarnar, mas que muitas vezes é rechaçado como inútil ou perigoso. Esse movimento tem diversos momentos.

O primeiro momento já é conhecido: sob uma invocação de um estado presente, instalamo-nos "de súbito", como que por um salto, no passado em geral, em certa região do virtual, num certo nível de contração do passado. Isto constitui a invocação à lembrança. Somente após isso a lembrança tende a se atualizar, tornar-se imagem-lembrança e, com a atualização, constituir-se em consciência psicológica. Isso significa que não vamos do presente (percepção) ao passado (lembrança), mas, ao contrário, da lembrança à percepção.

É importante frisarmos que os níveis não são dados já prontos, pois sua existência é apenas virtual. Isso significa que também eles são criados sem cessar pela inteligência que os atravessa, em outras palavras, a lembrança se atualiza ao mesmo tempo em que o nível que a comporta também se atualiza. Como conseqüência, existe a coexistência virtual de todos os níveis na duração, cuja contração e distensão determinam a forma do cone, e existe a contração psicológica através da qual cada lembrança é atualizada simultaneamente no nível que lhe é próprio, tornando-se imagem, por mais distendido que seja tal nível.

Desse ponto em que a lembrança se atualiza junto com todo um nível de passado é preciso ainda fazer a divisão entre as duas coisas até encontrarmos as imagens distintas que correspondem a esta ou àquela lembrança. A lembrança se atualiza ao tornar-se imagem e remeter, numa espécie de circuito, à imagem-percepção e de volta àquela. Além disso, há uma interferência das imagens-lembranças na percepção atual, que se prolonga sempre em movimentos sensório-motores, operando uma decomposição do percebido em função da utilidade e da necessidade de ação do corpo (atitude dinâmica do corpo). As lembranças intervêm na medida em que se assemelham à percepção, prolongando-se 
nos movimentos da percepção. Enfim, existe o movimento mecânico do corpo que reconduz ao objeto, restituindo-lhe sua integridade. Mas existe ainda um último aspecto da atualização da lembrança. A lembrança pura, como vimos, é simultânea ao presente que ela foi. A lembrança tende a atualizar-se numa imagem que é contemporânea desse presente. Qual seria então sua utilidade, se ela não viria mais que duplicar a imagem-percepção? Acontece que não se trata de um duplo, pois a lembrança se atualiza em função de um novo presente, em relação ao qual ela é passado, porque o presente não cessa de passar. Há, desse modo, um deslocamento através do qual o passado apenas se atualiza em função de um outro presente que não aquele que ele foi.

\section{Uma ou várias durações?}

Tendo seguido as linhas divergentes discernindo, para além da experiência, as diferenças de natureza entre a percepção e a lembrança, a matéria e a memória, o presente e o passado, devemos agora, seguindo o método de Bergson, reencontrar o ponto de unidade que nos deve levar ao aspecto monista de sua filosofia. Não basta afirmar que entre a imagem-lembrança e a percepção-imagem não há mais que diferenças de grau desde a atualização da lembrança tende a apagar a sua diferença de natureza em relação à percepção. Bergson assevera que, sendo o passado coexistente com seu próprio presente e consigo mesmo em diversos níveis de contração, é preciso que o próprio presente seja apenas o mais contraído nível do passado. Com isso, existe uma unidade ontológica entre presente e passado, percepção pura e lembrança pura, entre a matéria e a memória, cujas diferenças são diferenças de contração e distensão.

Inserimo-nos na matéria através do presente, como grau mais contraído do passado. Por conseguinte, a matéria é um passado infinitamente distendido, a ponto de o momento precedente desaparecer quando o seguinte aparece. O dualismo entre extenso e inextenso é suprimido: a percepção é extensa posto que a sensação é uma operação de contração de vibrações também extensas e dilatadas. O próprio movimento é atribuído às coisas, tanto fora de mim quanto em mim, implicando que as coisas materiais tanto quanto o Eu [Moi] participem diretamente da duração. Subsiste assim um monismo em que tudo se resume a diferentes estados de contração ou distensão da duração. 
Ora, mas isto não viria restabelecer as falsas noções de intensidade, em que os mistos eram analisados em termos de diferenças de grau, na medida em que contração e distensão não passariam justamente disso: diferenças de grau ou intensidade?

Além disso, como a duração se dissipa em tantas diferenças de intensidade (contração-distensão), é possível ver aí a transposição do dualismo num certo "pluralismo quantitativo"? Afinal, a duração é uma só ou várias?

Deleuze rastreia as hipóteses acerca da pluralidade ou não das durações ao longo da obra de Bergson. Duas hipóteses desenvolvidas inicialmente parecem não ser suficientes: primeiro, a que afirma a coexistência virtual de numerosas durações distintas como se o universo todo fosse uma memória em que todas as coisas coexistissem como durações mais ou menos dispersas, mais ou menos tensas; depois, a que retira das coisas materiais uma duração própria e as vê como participantes apenas da duração do universo como um todo e de nossa duração psicológica relativa. Mas Bergson vai apresentar como mais satisfatória uma terceira hipótese, que é justamente a que postula uma só duração, um monismo do Tempo, do qual tudo participaria: nossas consciências, os viventes e as coisas materiais. Um Tempo uno, universal e impessoal. Os motivos para a surpreendente escolha de Bergson estariam, segundo Deleuze, no seu confronto com a teoria da Relatividade.

Bergson teria reprovado a Einstein ele ter confundido os dois tipos de multiplicidade, virtual e atual, ao situar o tempo, como quarta dimensão do espaço, na categoria das multiplicidades atuais, numéricas e descontínuas (que Bergson opunha, como vimos, às multiplicidades virtuais, contínuas e qualitativas) e a partir daí afirmar a pluralidade do tempo. ${ }^{5}$ Para o filósofo, a resolução do problema de saber se o tempo é uno ou múltiplo decorreria de uma outra questão, a de saber qual é a multiplicidade própria do tempo. A duração é, afinal, uma multiplicidade, mas de que tipo?

Por que motivo o vôo de um pássaro que observamos e o murmúrio de nossa vida interior, que formam fluxos de duração diferentes, podem ser ditos simultâneos ou coexistentes? Porque eles estão contidos num terceiro fluxo, porque minha duração se desdobra e se reflete numa outra que a contém, ao mesmo tempo em que ela mesma contém em si o

5 Os detalhes da crítica de Bergson ao modo como o tempo é definido na teoria da Relatividade, tal como comentada por Deleuze, encontram-se em Bergsonismo, pp. 62-8. 
vôo do pássaro. Através da percepção, minha duração é capaz de revelar e englobar outras durações, simultâneas entre si, e também simultaneamente é capaz de englobar-se a si mesma ao infinito da duração.

Recordemos que a duração é uma multiplicidade virtual que muda de natureza a cada vez em que se divide, e tal mudança de natureza corresponde ao seu processo de atualização. Se nós nos colocamos no virtual, então é necessário admitir que há um tempo único, uma só duração. Mas existe a divisão do tempo desde que ela seja feita atualmente, ou seja, os diferentes fluxos da duração devem ser vividos ou ao menos pensados como podendo sê-lo. Nesse sentido, vemos que os fluxos comunicam-se num só e mesmo Tempo, que é sua condição:

Uma mesma duração vai recolher ao longo de sua rota os acontecimentos da totalidade do mundo material; e nós poderemos então eliminar as consciências humanas que havíamos inicialmente disposto de quando em quando como outras tantas alternâncias para o movimento do nosso pensamento; haverá tãosomente o tempo impessoal, em que se escoarão todas as coisas. ${ }^{6}$

A nossa própria duração, portanto, é ao mesmo tempo um fluxo, com suas diferenças de natureza e diferenças de contração e de distensão, e representante do Tempo no qual se abismam todos os fluxos.

Com isso, teria sido possível a Bergson conciliar as diferenças de natureza que existem entre os fluxos atuais da duração com as diferenças de distensão ou contração que há na virtualidade da duração. E esta mesma duração como multiplicidade virtual é o único e mesmo Tempo. O Tempo é uma multiplicidade, mas não é múltiplo e sim uno.

Como conceber então que Bergson assevere a distinção real entre o espaço e o tempo, se o tempo é concebido justamente como multiplicidade virtual, isto é, se há uma coexistência virtual dos graus de distensão e contração da duração que determinam a própria existência material? Justamente porque matéria e espaço não são o mesmo. A matéria é a duração infinitamente distendida; perdendo em tensão, esses momentos relaxados da duração ganham em extensão. Se esse movimento de distensão fosse impulsionado até o fim, se fosse levada ao extremo essa linha de diferenciação, aí sim obteríamos o espaço, como o extremo que não mais se combina com a duração. O espaço é, portanto, a representação do termo em que chegaria o movimento de distensão da

6 Bergson, H. Durée et Simultanéité. 4. ${ }^{a}$ ed., p. 59. Apud Deleuze, 1999, p. 65. 
matéria, embora a matéria nunca deixe de ser um mínimo de contração pela qual ela participa da duração, melhor, pela qual é duração. Pois a duração é a contração da matéria e a matéria é a distensão da duração. Perceber é contrair numa qualidade sentida milhões de vibrações extensivas, ou seja, todas as nossas sensações são contrações da matéria, são elas mesmas extensas, embora tenham uma infinidade de graus diferentes. De outro lado, a duração nunca se contrai a ponto de deixar de ser matéria. O presente, lembremos da imagem do cone, é o ponto mais contraído de nossa duração, mas ele não subsiste independentemente de uma matéria infinitamente distendida, que é o passado e que forma os infinitos níveis do cone.

Não é possível ao espaço, como grau mais distendido do tempo-duração, nem ao tempo, como grau mais contraído do espaço-matéria, adquirirem independentemente um estado de pureza. O espaço não deixa de ser a contração da duração e o tempo não cessa de ser distensão da matéria. Contudo é possível à inteligência não apenas o conhecimento da matéria, mas dominá-la e utilizá-la em seu favor. A inteligência encontra sua forma com a matéria, no mais distendido, e encontra seu sentido com a duração, no ponto mais contraído que lhe permite dominar a matéria. Só pode haver assim uma gênese simultânea da matéria e da inteligência: a inteligência se contrai na matéria ao mesmo tempo em que a matéria se distende na duração, encontrando no extenso sua forma comum. Mas à inteligência é possível levar essa forma a um grau de distensão que sozinha a matéria nunca teria atingido, esse grau de distensão é o espaço puro.

\section{O impulso vital como movimento de diferenciação}

Mas, afinal, como conciliar que passado e presente diferem por natureza com a afirmação de que o presente é apenas o nível ou grau mais contraído do passado? É possível sustentar, ao mesmo tempo, o dualismo das diferenças de natureza e o monismo dos graus de distensão e de contração que implicavam um Tempo único? Segundo Deleuze, a conciliação é possível desde que consideremos que há momentos diferentes do método utilizado por Bergson, quais sejam:

(1) a divisão dos mistos ("viravolta" da experiência): começamos por decompor os mistos que nos são dados pela experiência, descobrindo as articulações do real, isto é, as diferenças de natureza entre as ten- 
dências atuais que partilham o misto, como entre o espaço e a duração, a matéria e a memória, o presente e o passado, etc.;

(2) a neutralização do dualismo: as diferenças de natureza não remontam exatamente às duas tendências, já que apenas uma das duas direções é portadora de diferenças de natureza e a outra é portadora apenas de diferenças de grau. A duração é que apresenta as diferenças de natureza e define-se como diferença em relação a si, enquanto a matéria apresenta exclusivamente diferenças de grau. A memória é diferença, a matéria é repetição;

(3) monismo (reviravolta): coexistência virtual de todos os graus da duração, todos os níveis de distensão e contração coexistem num tempo único, também virtual, que é a natureza em si mesma. A duração, como diferença de natureza em si e para si, é a natureza naturante, a matéria, enquanto diferença de grau fora de si e para nós, é a natureza naturada. A duração é o mais contraído grau da matéria e a matéria o grau mais distendido da duração. Não há mais dualismo entre as diferenças de natureza e de graus pois todos os graus coexistem numa mesma Natureza, e esta Natureza se exprime duplamente: como diferenças de natureza e como diferenças de grau;

(4) dualismo reencontrado: faz-se necessário precisar a noção de virtual e reencontrar o dualismo a partir do monismo, em outras palavras, devemos lidar com o conceito de impulso vital como uma virtualidade em vias de atualizar-se ou de diferenciar-se, ou ainda poderíamos falar da totalidade em vias de dividir-se em direções divergentes. Bergson exemplifica: a vida se divide em planta e animal, o animal desdobra-se em instinto e inteligência, e assim indefinidamente de modo que a vida se confunde com esse movimento de diferenciação em séries ramificadas. Há duas causas da diferenciação: a causa externa, porque a duração se atualiza a partir dos obstáculos que encontra na matéria, na medida em que ela se insere e contrai a extensão; a causa interna, pois a duração se diferencia em si mesma, afirmando-se e prolongando-se por "uma força interna explosiva". Duração e vida são, nesse movimento, termos intercambiáveis.

Diferenciar-se é atualizar-se porque tal movimento supõe uma totalidade primordial e esta totalidade é virtual e procede por dissociação, seguindo linhas de diferenciação que divergem por natureza sem que em cada linha o todo deixe de subsistir sob certo aspecto, dando testemunho de sua origem indivisa; por exemplo, um certo instinto na inteligência ou uma nebulosa de inteligência no instinto. Assim, a virtualidade persiste sempre através de suas linhas divergentes atuais a que se 
chega através da diferenciação. Outro exemplo, o impulso vital se dissocia a cada instante em dois movimentos, distensão e contração, o primeiro recai na matéria, o segundo se eleva na duração. Subsiste uma diferença de natureza entre os dois lados da divisão, mas o dualismo que se tem aqui não é o mesmo dualismo da primeira etapa do método, em que um misto impuro era decomposto,; o que se tem nesta quarta etapa do método é um dualismo genético, porque ele se origina da diferenciação de um Puro. Esse Puro, como sabemos, é o virtual ou a virtualidade do tempo uno. Mas em que consiste a natureza desse virtual?

O movimento de diferenciação não é uma relação entre o possível e o real, mas entre o virtual e o atual. Pois o virtual, que pode ou não se tornar atualizado no presente, é no entanto real no passado ou na memória; o possível, por sua vez, embora possa ser atual como possibilidade presente de que algo possa ser realizado no futuro, nunca é real enquanto não for "realizado", o possível não tem realidade. O que interessa especialmente nessa distinção é que o virtual possui como tal uma realidade enquanto o possível pode ou não se realizar. Isso significa, em termos do movimento ontológico de diferenciação, que na passagem do virtual para o atual nada se perde em realidade, na medida em que o virtual é tão real quanto o atual, enquanto a passagem do possível para o real seria a passagem de algo que não tem realidade para algo real, absurdo lógico que Deleuze parece rechaçar. ${ }^{7}$

A passagem do possível para o real seguiria duas regras: semelhança e limitação. O domínio do real seria uma limitação do domínio do possível que ele realiza porque não são todas as possibilidades que podem se realizar: alguns possíveis são impedidos ou rechaçados, enquanto outros passam ao real.

Mas, se se diz que o real preexistia ou estava pré-formado no possível que realiza, não seria porque extraímos o possível do real após este ter-se efetivado? Nesse sentido, ao invés de o real estar dado como possibilidade que viria a efetivar-se, na verdade, o possível não passaria de uma imagem fictícia que abstraímos do real uma vez que ele tenha acontecido. Desse modo, seria falso falar de uma passagem do possível para o real porque, inversamente, é o possível que é abstraído arbitrariamente do real e pressupõe já sua realização.

Assim, na passagem do possível para o real existiria uma pseudo semelhança, a saber, o real não se assemelharia ao possível que realiza,

7 Cf. Hardt, 1996, pp. 29-55. 
mas o possível é que se assemelha ao real já efetivado. De qualquer forma, eles não diferem propriamente já que o real é equivocadamente concebido como presente na imagem do possível que realiza, ou seja, a realidade assemelhar-se-ia ao possível na medida em que ele preexistiria à realidade como possibilidade.

Ao contrário, o movimento do virtual para o atual não segue essas regras de semelhança e limitação, mas é guiado pela diferença/divergência e pela criação: o atual não se assemelha à virtualidade que ele encarna e, desse modo, para atualizar-se, o virtual deve criar positivamente suas linhas de atualização. É próprio da virtualidade atualizar-se diferenciando-se e criando linhas de diferenciação e não pode ser outro o seu modo de atualização. O que vem primeiro é a diferença tanto entre o virtual de que se parte e os atuais a que se chega, quanto à diferença entre as próprias linhas divergentes. E o próprio evolucionismo nos lembra que a vida é produção de diferenças. Mas o evolucionismo falha ao conceber as variações vitais como determinações atuais enquanto a evolução de fato acontece do virtual aos atuais, como atualização e, portanto, criação. Pois a diferença pode ser vivida e pensada apenas como diferença interna, como "tendência para mudar", as variações seguem linhas divergentes e, por fim, implicam uma virtualidade que se atualiza nessas linhas. Em outras palavras, a evolução biológica não vai de um atual a outro atual, mas de um virtual aos atuais inscritos ao longo de uma série ramificada.

Com isso, podemos responder à questão central: de que modo o Virtual tem o poder de diferenciar-se? O Virtual tem uma realidade, estendida a todo o Universo, que consiste numa gigantesca memória com todos os graus coexistentes de distensão e contração em suas inumeráveis diferenças de nível. Cada nível ou grau possui alguns "pontos brilhantes" que são, assim como o próprio nível, virtuais. Tanto os níveis quanto os pontos são as multiplicidades virtuais que pertencem a um tempo único e são a própria realidade desse Virtual. Quando a virtualidade se diferencia, ela o faz segundo linhas divergentes, mas cada linha corresponde a tal ou qual grau da virtualidade. Quando há a atualização, deixa de existir a coexistência do todo virtual, há linhas de atualização nesta ou naquela direção, sendo sucessivas ou simultâneas, contudo, cada linha corresponde a um dos graus que coexistem no virtual, separando um grau dos outros, ignorando o que se passa nos outros. Em suma, o que coexiste no virtual deixa de coexistir no atual e se distribui em linhas não somáveis, cada uma delas retém o todo apenas sob um certo ponto de vista, a vida quando se contrai numa espécie per- 
de contato, quase completamente, com o resto de si própria. Assim, as linhas de diferenciação são criadoras e o que elas criam é o representante físico, vital ou psíquico do nível ontológico que elas atualizam. Além disso, cada linha de vida se relaciona com um tipo de matéria que é justamente a partir de que o vivente fabrica para si um corpo ou uma forma.

Somente em relação ao resultado dessas linhas, isto é, os atuais, é que se pode falar em gradação ou oposição ou em termos de diferença de grau, como se um fosse o negativo do outro ou a sua inversão ou, ainda, um obstáculo: a matéria, por exemplo, como obstáculo para o impulso vital e a materialidade como inversão do movimento da vida. Em relação ao movimento que produz os atuais, que remete à virtualidade que neles se atualiza, não há dúvida que a diferenciação é sempre criação, que a diferença é essencialmente positiva e criadora.

Não há dúvida que há um Todo e este é a duração ou o tempo, mas esse todo não é dado: é virtual. As linhas divergentes que resultam de seu movimento de atualização já não se assemelham a ele e não são mais reuníveis num todo, permanecendo exteriores umas às outras. No atual há um pluralismo irredutível. Bergson veria um certo finalismo nesse movimento da vida, não como meta previamente definida, mas sim enquanto a vida opera em direção a alguma coisa. Tais direções não preexistem mas são elas mesmas criadas no movimento de atualização que as percorre. Ao diferenciar-se, a vida cria os meios para a distinção daquilo que se emaranhava no seio do virtual.

Mas de que modo a duração tem acesso atualmente à consciência de si, ela que é virtualidade, em outras palavras, em que condições a vida que é, de direito, memória, consciência e liberdade torna-se memória, consciência e liberdade de fato? Na linha de diferenciação que é o homem, que Bergson define como a "razão de ser" de todo movimento de atualização. Pois somente o homem é capaz de reencontrar todos os níveis de distensão e contração do virtual, mesmo as durações que lhe são inferiores ou superiores são ainda interiores a ele, a diferenciação que cria, numa direção aberta, vale para o todo e é capaz de exprimir um todo aberto. Apenas o homem é capaz de baralhar os níveis ou planos distintos de atualização, ultrapassando seu próprio plano para chegar a exprimir a Natureza naturante. Como isso é possível? É possível porque no estado de matéria cerebral do homem, segundo não mais do que as propriedades físico-químicas da matéria, quando ela recebe uma excitação, ela seleciona uma reação, criando entre a excitação e a reação um intervalo. É esse intervalo que torna possível a inteligência pois é nele justamente que se infiltra a memória, que toda a memória e liber- 
dade se tornam atuais: através do corpo podemos nos instalar de súbito no passado puro. O impulso vital soube criar com a matéria, sobre a linha de atualização do homem, um meio de triunfar sobre o determinismo da natureza.

Há ainda um outro intervalo intracerebral de suma importância para o homem e para explicar o privilégio do homem em relação às outras espécies e linhas divergentes. Trata-se do intervalo entre a inteligência e a sociedade, isto é, entre o egoísmo que a inteligência procura preservar e as exigências sociais sob a forma de obrigações, que por definição não têm fundamento racional, uma espécie de "instinto virtual", um equivalente de instinto que a inteligência guarda em si ao separarse dele, de acordo com a lei de diferenciação. Esta é a "função fabuladora", responsável pela criação de deuses e religiões, ela faz com que seja natural e necessário que a própria inteligência crie para si representações fictícias e é responsável por persuadir a inteligência a ser do interesse dela ratificar a obrigação social.

O que se insere nesse intervalo inteligência-sociedade é, segundo Bergson, a emoção, que difere ao mesmo tempo da inteligência e do instinto, da resistência do egoísmo inteligente e da pressão social quase instintiva. A emoção aqui tem de ser vista como elemento puro, uma essência que se difunde pela natureza, como a transcendência do amor que uma música exprime; introduzimo-nos numa certa emoção por intermédio dela mesma, como passantes levados a dançar. A emoção rompe a circularidade que há no constrangimento exercido pela sociedade e na contestação do indivíduo, tal como a Memória rompe o círculo excitação-reação, encarnando-se em imagens. A emoção criadora é ela mesma encarnação da memória cósmica, atualização simultânea de todos os níveis da memória, liberando o homem do seu nível e fazendo dele um criador ao ocorrer em algumas almas privilegiadas. É a emoção criadora que cria a intuição na inteligência. As grandes almas são antes as dos artistas ou dos místicos que a dos filósofos porque estes não são ainda suficientemente penetrados pela emoção-intuição que lhes permitiria aceder à criação, à totalidade criadora, como é capaz o místico, como é capaz uma filosofia que vai além dos dados da experiência, seguindo suas linhas de diferença até o ponto virtual em que todas as linhas se reencontram.

Deleuze desdobra assim os progressos da filosofia de Bergson a partir de seus conceitos fundamentais. A Duração define uma multiplicidade virtual daquilo que difere por natureza; a Memória é a coexistência virtual de todos os graus de diferença nessa multiplicidade; todos os ní- 
veis dessa virtualidade e o Impulso vital apontam para a atualização do virtual a partir de linhas de diferenciação que correspondem aos graus ou níveis, até a linha de diferenciação que é o homem, na qual o Impulso vital toma consciência de si.

FORNAZARI, S. K. The bergsonism of Giles Deleuze. Trans/Form/Ação, (São Paulo), v.27 (2), p.31-50, 2004.

- ABSTRACT: The text is a presentation of Gilles Deleuze's interpretation of Henri Bergson's philosophy. It aims at focus on subjects that deleuzean philosophy should return to, developing them in Différence et répetition and from this work. Among the most outstandings, we find the affirmative ontology subject, that involves the passage from virtual to actual through being differentiation process. Being doesn't stop to have existence by actualizing itself, but it differentiates itself in this process, being individualized as things. Being is thus pre-individual and pre-subjective. In Bergson, there should be a virtual coexistence of all differences degrees in duration.

- KEYWORDS: intuition; virtual; actual; differentiation; memory

\section{Referências bibliográficas}

BERGSON, Henri. Matéria e memória. Tr. Paulo Neves. 2. ${ }^{a}$ ed., São Paulo: Martins Fontes, 1999.

DELEUZE, Gilles. Bergsonismo. Tr. Luiz Orlandi. São Paulo: Ed. 34, 1999.

Diferença e repetição. Tr. Luiz Orlandi e Roberto Machado. Rio de Janeiro: Graal, 1988.

"L'immanence: une vie..." In: Philosophie, n. 7, Paris: set. 1995.

HARDT, Michael. Gilles Deleuze: um aprendizado em filosofia. Tr. Sueli Cavendish. São Paulo, Ed. 34, 1996.

SILVA, Valéria L. O empirismo transcendental na filosofia de Gilles Deleuze. Dissertação de mestrado. São Paulo, Universidade de São Paulo, 2001. 